\title{
Kinetics of NMDA Channel Opening
}

\author{
Jeffrey A. Dzubay and Craig E. Jahr \\ Vollum Institute, Neuroscience Graduate Program, Oregon Health Sciences University, Portland, Oregon 97201
}

\begin{abstract}
The period required for NMDA channels to open for the first time after agonist binding (the first latency) was estimated in outside-out patch recordings from rat hippocampal neurons using fast-application techniques and the open channel blocker MK-801. In the presence of MK-801, brief applications of L-glutamate or the low-affinity agonist L-cysteate resulted in a similar amount of block despite the much shorter period of channel activation by L-cysteate. A brief coapplication of L-glutamate and MK-801 resulted in a block similar to that found with an application of L-glutamate in a
\end{abstract}

background of MK-801. These results, along with our findings that MK-801 does not block desensitized receptors, indicate that NMDA channels have a mean first latency of $\sim 10 \mathrm{msec}$, consistent with a peak open probability near 0.3 . If NMDA channels at synapses behave similarly, relatively few channels would be required to produce the postsynaptic calcium transient associated with synaptic plasticity and developmental regulation.

Key words: ion channels; NMDA; kinetics; open probability; first latency; EPSC time course
In the vertebrate CNS, synaptic release of the excitatory neurotransmitter L-glutamate results in activation of NMDA receptor channels in the postsynaptic membrane that can last for several hundred milliseconds (Hestrin et al., 1990; Lester et al., 1990). The high affinity of the NMDA receptor for L-glutamate results in this prolonged channel activity because of the slow unbinding of agonist (Lester et al., 1990; Patneau and Mayer, 1990; Clements and Westbrook, 1991; Gibb and Colquhoun, 1991, 1992; Lester and Jahr, 1992). Two schemes describing the single-channel events that underlie a macroscopic response to a brief pulse of L-glutamate have developed in parallel.

In the first scheme, NMDA channels open, on average, $\sim 10$ msec after agonist binding. The scheme is based on experiments using MK-801 (Jahr, 1992), which blocks NMDA channels very rapidly after they open but unblocks very slowly at negative holding potentials, and then only when the agonist is bound (Huettner and Bean, 1988). In the presence of $20 \mu \mathrm{M} \mathrm{MK-801,} \mathrm{a}$ brief application of a saturating concentration of L-glutamate results in channel activity reflecting the first openings of individual channels. This is because any channel that opens for more than $\sim 2$ msec will be blocked essentially irreversibly by $20 \mu \mathrm{M}$ MK- 801 . Therefore, in a patch containing many NMDA channels, the macroscopic current recorded in MK-801 approximates a firstlatency distribution (Jahr, 1992).

This distribution can be fitted with a single exponential with a time constant of $\sim 13 \mathrm{msec}$, indicating that most channels open for the first time soon after agonist binding. If this first-latency distribution is deconvolved from a response in the absence of MK801 , the resulting distribution represents the conditional probability that a channel is open at time $t$ given that it was open at $t=$ 0 . This distribution decays slowly, lasting several hundred milli-

\footnotetext{
Received Feb. 15, 1996; revised April 3, 1996; accepted April 9, 1996.

This work was supported by National Institutes of Health Grant NS21419. We thank Drs. Dwight Bergles, Jeffrey Diamond, and Indira Raman for helpful comments; Dawn Shepherd for participation in preliminary experiments; and Jeffrey Volk for cell culture preparation.

Correspondence should be addressed to Craig E. Jahr, Vollum Institute L474, Oregon Health Sciences University, 3181 SW Sam Jackson Park Road, Portland, OR 97201-3098.

Copyright (C) 1996 Society for Neuroscience $0270-6474 / 96 / 164129-06 \$ 05.00 / 0$
}

seconds. Taken together, these distributions describe channel behavior in which openings occur with moderately high probability soon after agonist binding and repeatedly open and close until dissociation of the agonist hundreds of milliseconds later (Jahr, 1994). It also was estimated that at the peak of the patch response to L-glutamate, $\sim 30 \%$ of the channels in the patch were open simultaneously. This agrees well with other patch and whole-cell measurements (Lin and Stevens, 1994; Benveniste and Mayer, 1995; Rosenmund et al., 1995) and some synaptic measurements (Hessler et al., 1993).

In the second scheme, most NMDA channels open after a considerable delay. The distribution describing the conditional probability that a channel is open at time $t$ given it was open at $t=$ 0 was constructed for this scheme by aligning groups of channel openings, called "super-clusters" (Gibb and Colquhoun, 1991, 1992), recorded at low agonist concentrations (Edmonds and Colquhoun, 1992). In contrast to the first scheme, this conditional open-probability distribution decays quickly, from 1 to 0.26 in 10 msec, indicating that after the initial burst or cluster of openings, the likelihood of subsequent openings is very low (Edmonds and Colquhoun, 1992). Deconvolving the conditional open-probability distribution from the response of a patch to a brief pulse of L-glutamate gives rise to a first-latency distribution that predicts that the majority of the channels open for the first time $>100$ milliseconds after the binding agonist and that the channels have a very low $\mathrm{P}_{\mathrm{o}}$. The low open probability is consistent with estimates using steady-state agonist applications (Huettner and Bean, 1988; Traynelis and Cull-Candy, 1990) and some synaptic measurements (Rosenmund et al., 1993, 1995).

The present experiments were undertaken to determine which of these schemes best describes NMDA channel behavior in outside-out patches.

\section{MATERIALS AND METHODS}

Cell culture. Experiments were conducted on outside-out patches of rat hippocampal neurons grown in primary culture. Cells were taken from P1-3 rats and maintained in culture for 1-3 weeks (Lester et al., 1989).

Solutions. Recording pipettes were filled with a solution containing (in mM): cesium gluconate 140, $\mathrm{NaCl} 10$, HEPES 10, EGTA 10, and Mg-ATP 5, adjusted to $\mathrm{pH} 7.2$ with $\mathrm{CsOH}$, and kept on ice until use. External 

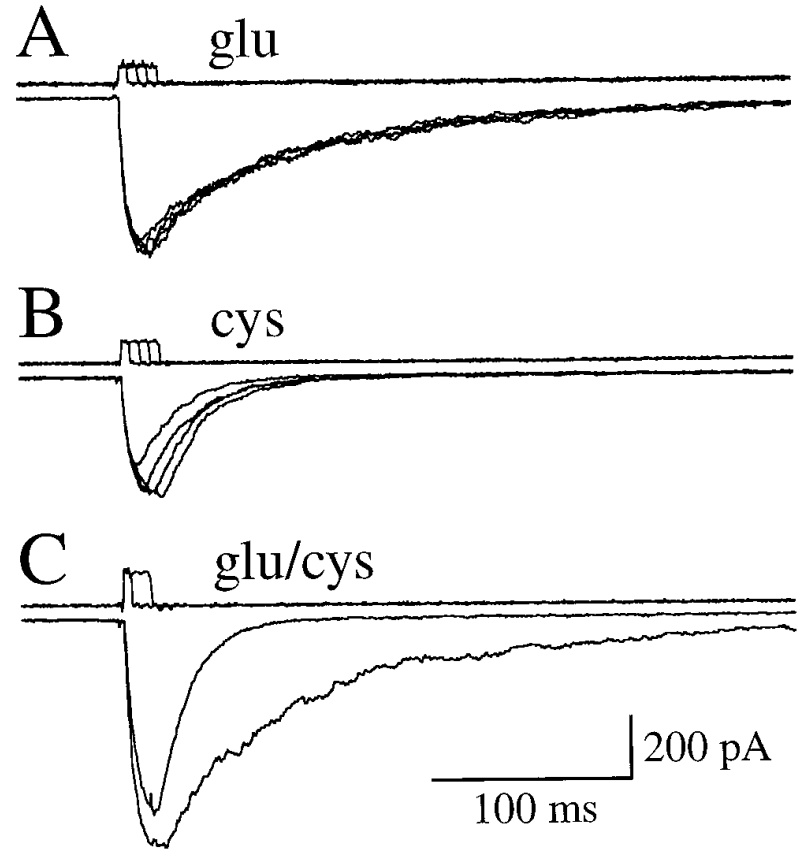

Figure 1. Decay time of NMDA channel responses depends on the agonist. $A$, Superimposed responses of a patch to $5,10,15$, and $20 \mathrm{msec}$ applications of $10 \mathrm{~mm}$ L-glutamate $(g l u)$. Each trace is an average of five sweeps; the different length applications were made successively and then repeated in a cyclic manner. $B$, Superimposed responses to $5,10,15$, and $20 \mathrm{msec}$ applications of $10 \mathrm{~mm}$ L-cysteate (cys) using the same protocol as in $A$. $C$, The average NMDA receptor response to a $15 \mathrm{msec}$ application of $10 \mathrm{~mm} \mathrm{~L}$-cysteate superimposed on the average response to a $5 \mathrm{msec}$ application of $10 \mathrm{~mm}$ L-glutamate in the same patch. $A-C$ are from different patches. Open-tip traces of the various length applications are superimposed above the patch responses. $V_{\mathrm{h}}=-60 \mathrm{mV}$.

solutions contained (in mM): $\mathrm{NaCl} \mathrm{160,} \mathrm{KCl} 3$, HEPES $10, \mathrm{CaCl}_{2} 0.2$, and $5 \mu \mathrm{M}$ NBQX and $20 \mu \mathrm{M}$ glycine, adjusted to $\mathrm{pH} 7.4$ with $\mathrm{NaOH}$. Highpurity salts were used in the external solution to minimize contaminating divalents. Internal and external solution osmolalities were 305-315 mOsms. Chemicals were obtained from the following sources: Sigma (St. Louis, MO; L-glutamate, L-cysteate, HEPES, EGTA, Mg-ATP, and gluconic acid); Mallinckrodt [Paris, France; KT ( $\mathrm{NaCl}$ )]; Aldrich Chemical [Milwaukee, WI; high-purity (Gold Label) $\mathrm{NaCl}, \mathrm{KCl}$, and cesium hydroxide]; Johnson Matthey (Ward Hill, MA; $\mathrm{CaCl}_{2}$ ); Bio-Rad Laboratories (Hercules, CA; glycine); RBI (Natick, MA; MK-801). NBQX was a gift from Novo Nordisk (Denmark).

Recording and perfusion techniques. Outside-out patch recordings were made with borosilicate glass pipettes (WPI, Sarasota, FL) pulled to a "bubble number" of 7.4-7.8 and occasionally lightly polished to final tip resistance of 1-4 M $\Omega$. Currents were sampled at $2 \mathrm{kHz}$ and low-passfiltered at $1 \mathrm{kHz}$ using an Axopatch 200A, AxoBasic software, and a TL-1 DMA interface (Axon Instruments, Foster City, CA). Solution exchanges were made with flow tubes attached to piezoelectric bimorphs (Vernitron, Bedford, OH), as described previously (Lester and Jahr, 1992; Tong and Jahr, 1994). Open-tip measurements were made at the end of each experiment to test the speed and consistency of the solution exchange. Data from patches with questionable exchange were not analyzed. The open-tip solution exchanges had a $10-90 \%$ rise time of $<500 \mu \mathrm{sec}$, the sampling interval. Patches were held at $0 \mathrm{mV}$ between agonist applications and at $-60 \mathrm{mV}$ during responses to agonists. Trials were separated by $15-20 \mathrm{sec}$ to allow recovery from desensitization. Statistical analysis was performed using InStat (Graph Pad Software, San Diego, CA). Reported values are given as mean $\pm \mathrm{SD}$. All experiments were performed at room temperature.

\section{RESULTS}

\section{Block by MK-801 is independent of agonist affinity}

NMDA channels activated by short pulses of high-affinity agonists remain active for longer periods than when bound by low-affinity
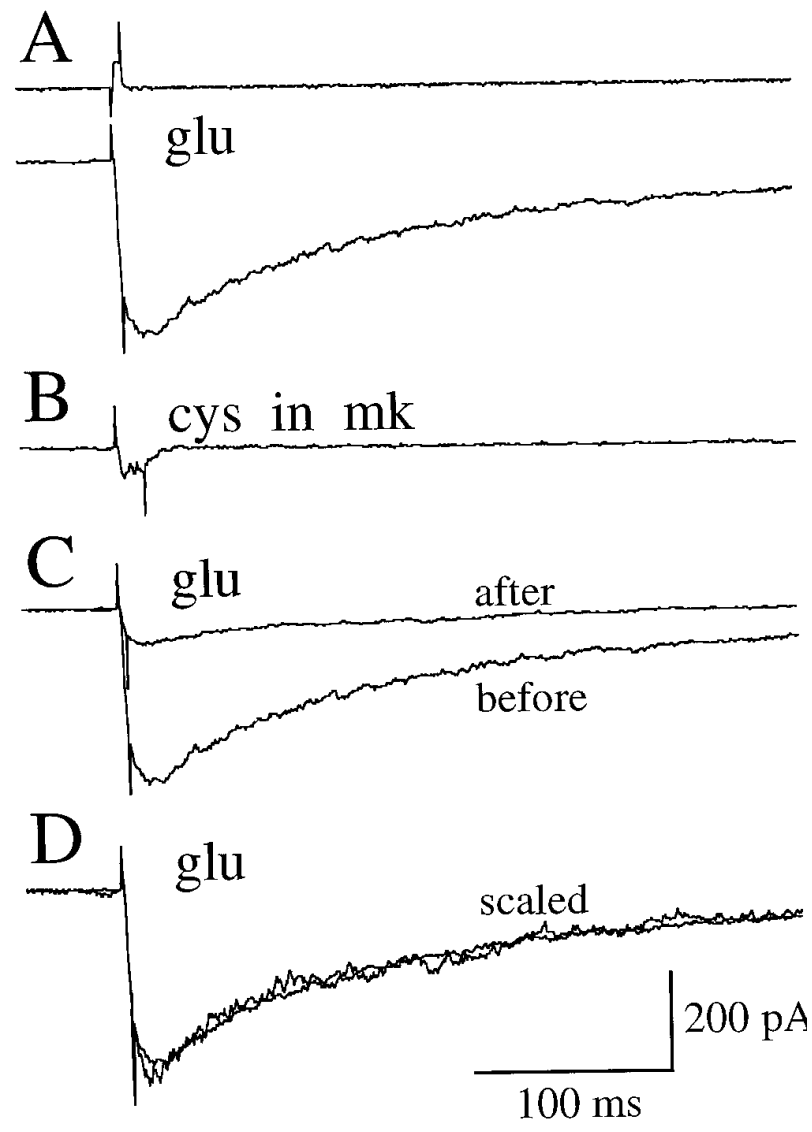

Figure 2. The magnitude of block by MK-801 is comparable for L-cysteate and L-glutamate responses. $A$, The average NMDA receptor response of an outside-out patch to a $5 \mathrm{msec}$ pulse of $10 \mathrm{mM}$ L-glutamate ( $g l u$ ) before MK-801 exposure. Above the response is the open-tip trace measured at the end of the experiment. $B$, A $15 \mathrm{msec}$ application of $10 \mathrm{~mm}$ L-cysteate in a background of $20 \mu \mathrm{M}$ MK-801, the blocking trial. $C$, Averaged responses to $5 \mathrm{msec}$ pulses of $10 \mathrm{~mm}$ L-glutamate before and after the MK-801 exposure, superimposed. $D$, Responses in $C$ scaled. All traces are from the same patch.

agonists (Lester and Jahr, 1992), because ligand-gated ion channels generally can open only while agonists are bound (Hille, 1992). Responses activated by brief applications of the low-affinity agonist L-cysteate decay much faster $\left(\tau_{1}=31 \mathrm{msec}, 95 \% ; \tau_{2}=164\right.$ $\mathrm{msec})$ than responses to L-glutamate $\left(\tau_{1}=68 \mathrm{msec}, 80 \% ; \tau_{2}=553\right.$ msec) (Lester and Jahr, 1992). If NMDA channels open only after prolonged bound times (the long first-latency scheme), then far fewer channels would be blocked by MK-801 during an L-cysteate response than during an L-glutamate response, because L-cysteate would unbind before most channels could open for the first time. However, if NMDA channels open soon after agonist binding (the short first-latency scheme), receptor activation by L-cysteate and L-glutamate should result in a similar degree of block. This prediction requires the behavior of the channels to be comparable while either agonist is bound, as evinced by the similarity of responses to long applications of the two agonists (Lester and Jahr, 1992).

It was necessary to determine the minimum application duration of saturating L-cysteate required to give a maximal response, because the unbinding rate of L-cysteate is much faster than that of L-glutamate. A response with maximal amplitude was achieved with a $15 \mathrm{msec}$ pulse of $10 \mathrm{~mm}$ L-cysteate (Fig. 1). The charge transfer during the first $20 \mathrm{msec}$ of the response was $89 \pm 10 \%$ of 

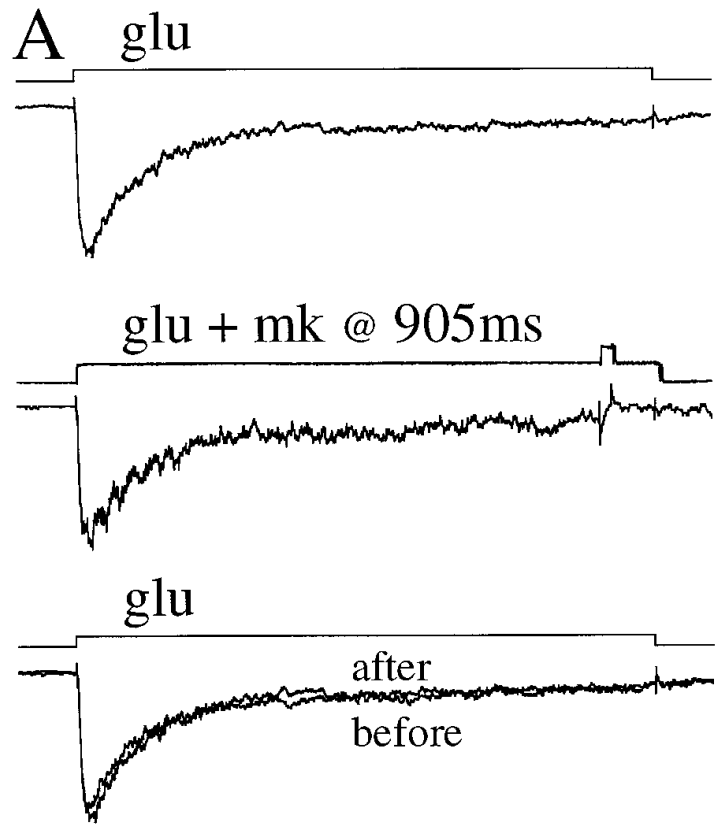
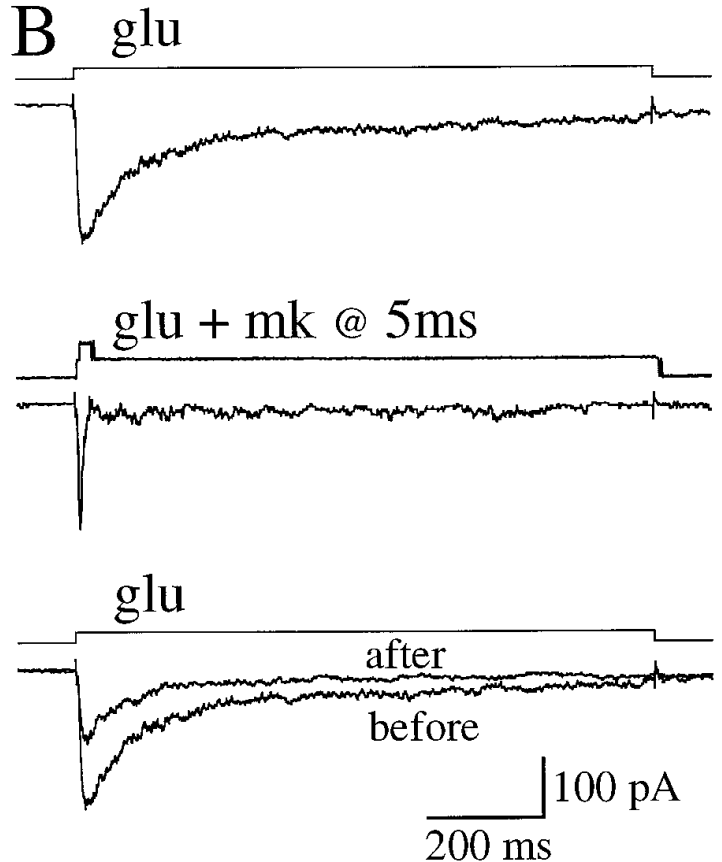

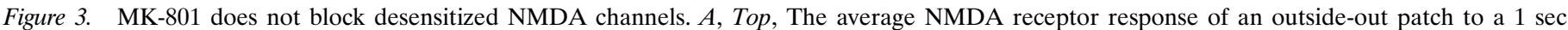

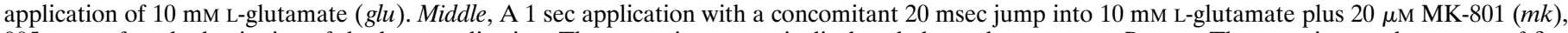

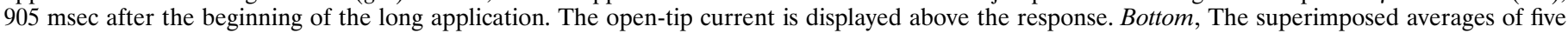

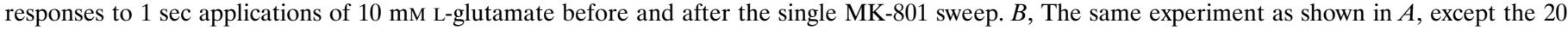

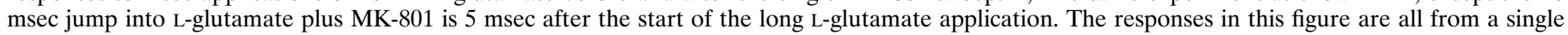
patch.

that produced by a $5 \mathrm{msec}$ pulse of $10 \mathrm{~mm}$ L-glutamate, whereas the total charge transfer with L-cysteate was only $23 \pm 9 \%$ of that with L-glutamate $(n=6)$. L-cysteate appears to be slightly less efficacious than L-glutamate at NMDA receptors, because $10 \mathrm{~mm}$ L-cysteate is a saturating concentration (Patneau and Mayer, 1990).

Control responses were elicited with a $5 \mathrm{msec}$ pulse of $10 \mathrm{~mm}$ L-glutamate before and then after a single trial consisting of a 15 msec pulse of $10 \mathrm{~mm}$ L-cysteate applied after equilibrating the patch in $20 \mu \mathrm{M} \mathrm{MK-801} \mathrm{(Fig.} \mathrm{2).} \mathrm{L-glutamate} \mathrm{was} \mathrm{used} \mathrm{for} \mathrm{the}$ control responses to allow comparison with the block using L-glutamate (Jahr, 1992). Charge transfer $(Q)$ was measured by integrating the averages of five of the control responses before and after the MK-801 trial, and the percent block was calculated as $\left(Q_{\text {before }}-\mathrm{Q}_{\text {after }}\right) / Q_{\text {before }}$. Consistent with the short first-latency scheme, the block observed using L-cysteate $(79 \pm 11 \%, n=7)$ was not significantly different ( $p>0.1$, Student's unpaired twotailed $t$ test) to that using L-glutamate $(70 \pm 10 \%, n=8)$ (Jahr, 1992).

\section{MK-801 does not block desensitized channels}

A concern with the previous experiments, in which MK-801 was continuously present, is the possibility that MK-801 may block receptors that are bound by ligand but in a nonconducting (e.g., desensitized) state, thereby resulting in an overestimate of the number of channels that open before agonist unbinding. To address this concern, a $1 \mathrm{sec}$ application of L-glutamate $(10 \mathrm{~mm})$ was used to desensitize a population of receptors. An application of this length results in an NMDA response that decays markedly while agonist is present (Fig. $3 A$, top trace). During this long application of L-glutamate, $20 \mu \mathrm{M}$ MK-801 was coapplied for 20 msec either $905 \mathrm{msec}$ into the application (Fig. $3 A$ ) or $5 \mathrm{msec}$ into the application (Fig. 3B). Five control responses to L-glutamate before and after the MK-801 trial were averaged and integrated to calculate the reduction in charge transfer caused by the exposure to MK-801 at the two times. The amount of block $\left[\left(Q_{\text {before }}-\right.\right.$ $\left.\left.Q_{\text {after }}\right) / Q_{\text {before }}\right]$ was significantly less when MK- 801 was applied at $905 \mathrm{msec}(19 \pm 16 \%$ block $)$ than at $5 \mathrm{msec}(51 \pm 17 \%$ block; $p=$ 0.009 , Student's two-tailed paired $t$ test, $n=6$ ). The amount of block was correlated with the charge transfer at the time of the block, as would be expected if MK-801 could only block open receptors. The ratio of the block at $905 \mathrm{msec}$ to the block at 5 msec $(38 \pm 32 \%)$ was not significantly different from the ratio of the charge transfer from $905-925 \mathrm{msec}$ to the charge transfer from $5-25 \mathrm{msec}(26 \pm 14 \% ; p=0.27$, Student's two-tailed paired $t$ test, $n=6)$. These results indicate that desensitized receptors are unavailable for block by MK-801.

\section{MK-801 blocks most channels in the first $\mathbf{1 0}$ msec}

To estimate more directly the average first latency of NMDA channels, patches were exposed to MK-801 only during a brief agonist application. If the short first-latency scheme is correct, a transient simultaneous exposure to L-glutamate and MK-801 should produce a significant block. However, if the long firstlatency scheme is correct, the majority of openings occur later in the response and little block should occur. The amount of block caused by a single $10 \mathrm{msec}$ pulse of $10 \mathrm{~mm}$ L-glutamate and $20 \mu \mathrm{M}$ MK-801 was measured as above by integrating the charge transfer under control conditions ( $5 \mathrm{msec}$ pulse of $10 \mathrm{~mm}$ L-glutamate, five sweeps in each average) before and then after the exposure to MK-801 (Fig. 4). This protocol resulted in an average block of 62 $\pm 10 \%$ measured in 10 patches. This amount of block is comparable ( $p>0.10$, Student's two-tailed unpaired $t$ test) to the $70 \pm$ $10 \%(n=8)(\mathrm{Jahr}, 1992)$ measured when the MK-801 was present 

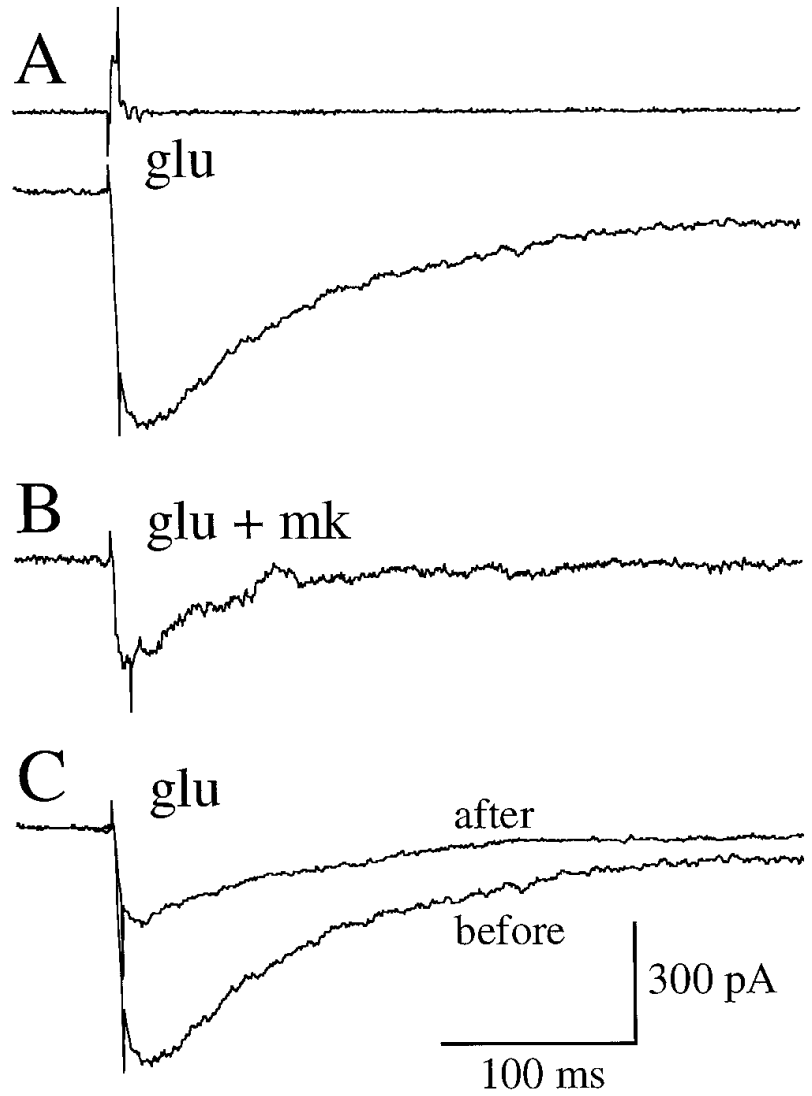

Figure 4. Brief exposure to L-glutamate plus MK-801 produces an amount of block similar to that found by applying L-glutamate in a background of MK-801. A, An average of five NMDA receptor responses of an outside-out patch to $5 \mathrm{msec}$ pulses of $10 \mathrm{mM} \mathrm{L-glutamate}(\mathrm{glu})$ before exposure to MK-801. The open-tip current is displayed above the response. $B$, The response of the same patch to a $10 \mathrm{msec}$ pulse of $10 \mathrm{~mm}$ L-glutamate and $20 \mu \mathrm{M} \mathrm{MK}-801(\mathrm{mk})$. $C$, The average in $A$ and an average of five responses after exposure to MK-801, superimposed.

throughout the blocking trial, and indicates that a large percentage of channels open within $10 \mathrm{msec}$ of binding L-glutamate.

It is possible that MK-801 can bind to a low-affinity site on the closed channel (e.g., in the external vestibule) from which it could block the channel once the pore opens tens of milliseconds after the end of the application. This would result in an underestimate of the average first latency. To address this possibility, a $4 \mathrm{msec}$ application of $10 \mathrm{~mm}$ L-glutamate was preceded at decreasing intervals by a $4 \mathrm{msec}$ pulse of $20 \mu \mathrm{M}$ MK-801 (Fig. 5). With each patch, three types of applications were made in succession and then repeated in a cyclical fashion three to six times: first a control trial with no pulse of MK-801, followed by a trial with a pulse of MK-801 completed $30 \mathrm{msec}$ before the start of the L-glutamate pulse, and finally a test trial with a pulse of MK-801 ending either $20,15,10,5$, or $3 \mathrm{msec}$ before the pulse of L-glutamate. Except for two long-lived patches, only one of the test times was attempted per patch.

In 17 patches, the trials with an application of MK-801 ending $30 \mathrm{msec}$ before the L-glutamate test pulse were $101 \pm 9.6 \%$ of the control response. A one-way ANOVA was performed with post hoc comparisons between the decreasing test intervals and the responses of the $30 \mathrm{msec}$ interval, all expressed as percentages of the control response in the same patch. The ANOVA gave a $p$ value of 0.182 , indicating the difference among the means was not
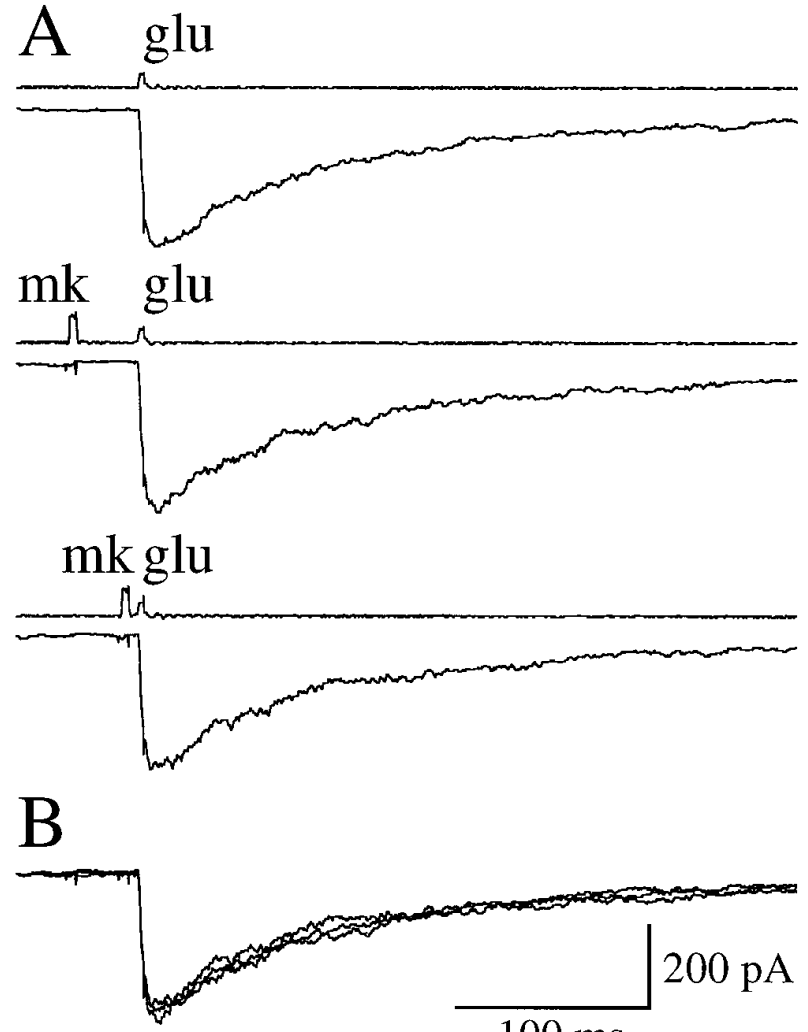

$100 \mathrm{~ms}$

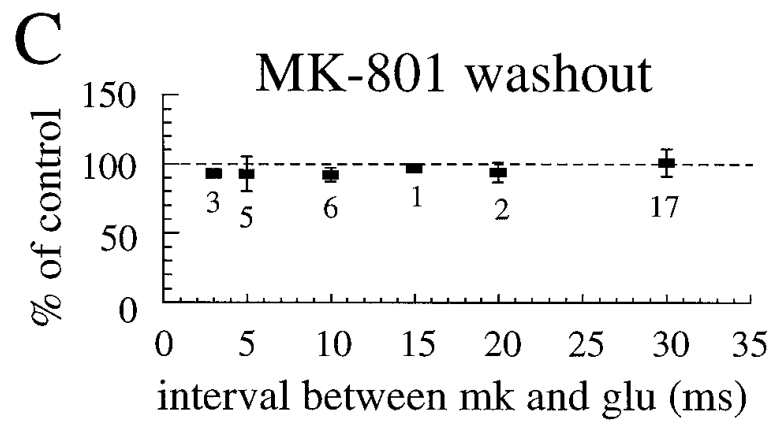

Figure 5. Rapid washout of MK-801. $A$, Three types of trials made in succession and then repeated cyclically. Top, Control trial, a single $4 \mathrm{msec}$ pulse of $10 \mathrm{~mm}$ L-glutamate $(\mathrm{glu})$. Middle, A $4 \mathrm{msec}$ pulse of $20 \mu \mathrm{M}$ MK-801 ( $\mathrm{mk}$ ) followed by a $4 \mathrm{msec}$ pulse of $10 \mathrm{mM}$ L-glutamate with a 30 msec interval between the two pulses. Bottom, Same as the middle trace, but with a 3 msec interval between the MK- 801 pulse and the L-glutamate pulse. Each trace is the average of three sweeps. The open-tip currents are displayed above each trace. $B$, The three traces shown in $A$, superimposed. All traces are from the same patch. $C$, A plot of the mean response for each time interval, expressed as percent of the control response in the patch in which the measurement was made. The numbers below the data points indicate the number of patches contributing to each mean, and the error bars are SDs.

significant. In addition, the Bonferroni $p$ values for individual comparisons with the $30 \mathrm{msec}$ interval were not significant.

\section{DISCUSSION}

Our results using concentration jumps with outside-out patches support the short first-latency scheme presented above. We have found that block by MK-801 is independent of agonist affinity; transient NMDA channel activity evoked by L-cysteate results in a block by MK-801 comparable to that of longer-lasting L-glutamate-induced activity. We also have shown that a brief 
coapplication of MK-801 and L-glutamate is sufficient to produce a block similar to that found when MK-801 is present throughout the trial. In addition, we have demonstrated that the block of desensitized receptors by MK-801 is unlikely to account for the large block produced by MK- 801 during a patch response. These results indicate that most of the channels that open before agonist dissociation do so for the first time within 10 milliseconds, and that the long decay of NMDA channel responses to brief pulses of L-glutamate is attributable to repeated openings of channels and not to long first latencies. This is consistent with the channels having a peak open probability near 0.3 in response to brief saturating concentrations of agonist (Jahr, 1992, 1994).

The conclusions of this study contrast with those of lowconcentration steady-state studies that require a low probability of opening and long first latencies to explain the slow NMDA response (Edmonds and Colquhoun, 1992). The disparity may be attributable to differences in the behavior of the channels under contrasting recording conditions. As has been suggested previously (Edmonds and Colquhoun, 1992), quick jumps into high concentrations may give rise to activations with a higher $\mathrm{P}_{\mathrm{o}}$ than those found in steady-state low-concentration experiments. Preliminary evidence to this effect was reported by Edmonds and Colquhoun (1992) and was explained by possible differences in the initial occupancies of the various kinetic states. An example of a kinetic model that could account for the differences between the experimental results is one that includes openings of receptors with one ligand bound.

Monoliganded receptor openings are not likely to occur at physiological concentrations of transmitter (Patneau and Mayer, 1990; Clements and Westbrook, 1991). However, the low agonist concentrations used in the steady- state experiments may increase the likelihood of such events, analogous to what is found with acetylcholine receptors (Dionne et al., 1978; Colquhoun and Sakmann, 1985; Colquhoun and Ogden, 1988) and $\mathrm{GABA}_{\mathrm{A}}$ receptors (Twyman et al., 1990). The saturating concentrations of agonists used in the present study result in doubly liganded receptors that may be more likely than monoliganded receptors to enter into the "high- $\mathrm{P}_{\mathrm{o}}$ periods" seen by many researchers (Jahr and Stevens, 1987; Howe et al., 1988; Gibb and Colquhoun, 1991, 1992). These periods of intense activity, with $\mathrm{a} \mathrm{P}_{\mathrm{o}}$ of $\sim 0.8$ (Gibb and Colquhoun, 1992), can last for hundreds of milliseconds and may contribute significantly to the macroscopic response evoked by brief applications of high concentrations of L-glutamate. In steady-state experiments using low concentrations of L-glutamate but high concentrations of glycine, the periods of high $\mathrm{P}_{\mathrm{o}}$ occurred about once a minute during continuous recording and yet contributed $22 \%$ of the openings (Gibb and Colquhoun, 1991). It is not known whether high- $\mathrm{P}_{\mathrm{o}}$ periods are dependent on agonist concentration, but this could explain the brevity of the aligned single-channel activations observed by Edmonds and Colquhoun (1992). In that study, high- $P_{\text {o }}$ periods were not reported, perhaps because of the very low concentrations of both L-glutamate and glycine used. These periods of intense activity could result in significant charge transfer late in the response, slowing the decay of the conditional open probability distribution.

Correlations in channel activity apparent in single-channel recordings (Gibb and Colquhoun, 1992; Edmonds et al., 1995) may be indicative of channel properties that could result in the discrepancy between the concentration jump experiments and those under steady-state conditions. Strong correlation between adjacent openings, between adjacent shut periods, and an inverse correlation between adjacent open and shut periods indicate that long openings more often are found near other long openings and brief closings. The extreme of this trend would be the high- $\mathrm{P}_{\mathrm{o}}$ periods mentioned above, and this behavior may result from a kinetic state favored by jumps into high agonist concentrations.

A recent study by Benveniste and Mayer supports the short first-latency-high- $\mathrm{P}_{\mathrm{o}}$ scheme. Using coapplications of the open channel blocker 9-aminoacridine (9-AA) and L-glutamate, they measured an absolute limit of $75 \mathrm{msec}$ on the first latency of NMDA receptors (Benveniste and Mayer, 1995). Coapplications of longer durations collected no additional channels in the openblocked state, as measured by the amplitude of tail currents evoked by a depolarizing pulse at the end of the application. In addition, after a $20 \mathrm{msec}$ coapplication, they noted a rise in inward current on returning to the control solutions that they interpreted as first openings of channels, similar to a response to L-glutamate in the absence of 9-AA. This response was only $27 \%$ of control, which suggests that $73 \%$ of the channels that would open in response to L-glutamate opened within $20 \mathrm{msec}$ of agonist presentation.

The single-channel behavior in agreement with our findings consists of an average first latency of $\sim 10 \mathrm{msec}$, a peak $\mathrm{P}_{\mathrm{o}}$ near 0.3 , and a significant number of channels exhibiting long-lasting bursting. If synaptic NMDA channels behave similarly to those in outside-out patches (Hessler et al., 1993) (see also Rosenmund et al., 1993, 1995), this short first-latency-high- $\mathrm{P}_{\mathrm{o}}$ scheme suggests that relatively few channels $(\sim 5-30)$ are required at individual synaptic sites to account for the small NMDA component of miniature excitatory synaptic currents (Bekkers and Stevens, 1989; Robinson et al., 1991; McBain and Dingledine, 1992; Silver et al., 1992). Very recently, it has been reported that calmodulin can regulate the $P_{o}$ of NMDA channels (Ehlers et al., 1996). This may account for the differences in estimates of $\mathrm{P}_{\mathrm{o}}$ in different preparations (Jahr, 1992; Hessler et al., 1993; Rosenmund et al., 1993, 1995).

\section{REFERENCES}

Bekkers JM, Stevens CF (1989) NMDA and non-NMDA receptors are co-localized at individual excitatory synapses in cultured rat hippocampus. Nature 341:230-233.

Benveniste M, Mayer ML (1995) Trapping of glutamate and glycine during open channel block of rat hippocampal neuron NMDA receptors by 9-aminoacridine. J Physiol (Lond) 483:367-384.

Clements JD, Westbrook GL (1991) Activation kinetics reveal the number of glutamate and glycine binding sites on the $N$-methyl-D-aspartate receptor. Neuron 7:605-613.

Colquhoun D, Ogden DC (1988) Activation of ion channels in the frog end-plate by high concentrations of acetylcholine. J Physiol (Lond) 395:131-159.

Colquhoun D, Sakmann B (1985) Fast events in single channel currents activated by acetylcholine and its analogues at the frog muscle endplate. J Physiol (Lond) 369:501-557.

Dionne VE, Steinbach JH, Stevens CF (1978) An analysis of the doseresponse relationship at voltage-clamped frog neuromuscular junctions. J Physiol (Lond) 281:421-444.

Edmonds B, Colquhoun D (1992) Rapid decay of averaged singlechannel NMDA receptor activations recorded at low agonist concentration. Proc R Soc Lond [Biol] 250:279-286.

Edmonds B, Gibb AJ, Colquhoun D (1995) Mechanisms of activation of glutamate receptors and the time course of excitatory synaptic currents. Annu Rev Physiol 57:495-519.

Ehlers MD, Zhang S, Bernhardt JP, Huganir RL (1996) Inactivation of NMDA receptors by direct interaction of calmodulin with the NR1 subunit. Cell 84:745-755.

Gibb AJ, Colquhoun D (1991) Glutamate activation of a single NMDA receptor-channel produces a cluster of channel openings. Proc R Soc Lond [Biol] 243:39-45. 
Gibb AJ, Colquhoun D (1992) Activation of $N$-methyl-D-aspartate receptors by L-glutamate in cells dissociated from adult rat hippocampus. J Physiol (Lond) 456:143-179.

Hessler NA, Shirke AM, Malinow R (1993) The probability of release at a mammalian central synapse. Nature 366:569-572.

Hestrin S, Sah P, Nicoll RA (1990) Mechanisms generating the time course of dual component excitatory synaptic currents recorded in hippocampal slices. Neuron 5:247-253.

Hille B (1992) Ionic channels of excitable membranes. Sunderland, MA: Sinauer.

Howe JR, Colquhoun D, Cull-Candy SG (1988) On the kinetics of largeconductance glutamate-receptor ion channels in rat cerebellar granule neurons. Proc R Soc Lond [Biol] 233:407-422.

Huettner JE, Bean BP (1988) Block of $N$-methyl-D-aspartate-activated current by the anticonvulsant MK-801: selective binding to open channels. Proc Natl Acad Sci USA 85:1307-1311.

Jahr CE (1992) High probability opening of NMDA receptor channels by L-glutamate. Science 255:470-472.

Jahr CE (1994) NMDA receptor kinetics and synaptic function. Semin Neurosci 6:81-86.

Jahr CE, Stevens CF (1987) Glutamate activates multiple single channel conductances in hippocampal neurons. Nature 325:522-525.

Lester RAJ, Jahr CE (1992) NMDA channel behavior depends on agonist affinity. J Neurosci 12:635-643.

Lester RAJ, Quarum ML, Parker JD, Weber E, Jahr CE (1989) Interaction of 6-cyano-7-nitroquinoxaline-2,3-dione with the $N$-methyl-Daspartate receptor-associated glycine binding site. Mol Pharmacol 35:565-570.

Lester RAJ, Clements JD, Westbrook GL, Jahr CE (1990) Channel kinetics determine the time course of NMDA receptor-mediated synaptic currents. Nature 346:565-567.

Lin F, Stevens CF (1994) Both open and closed NMDA receptor channels desensitize. J Neurosci 14:2153-2160.

McBain C, Dingledine R (1992) Dual-component miniature excitatory synaptic currents in rat hippocampal CA3 pyramidal neurons. J Neurophysiol 68:16-27.

Patneau DK, Mayer ML (1990) Structure-activity relationships for amino acid transmitter candidates acting at $N$-methyl-D-aspartate and quisqualate receptors. J Neurosci 10:2385-2399.

Robinson HPC, Sahara Y, Kawai N (1991) Nonstationary fluctuation analysis and direct resolution of single channel currents at postsynaptic sites. Biophys J 59:295-304.

Rosenmund C, Clements JD, Westbrook GL (1993) Nonuniform probability of glutamate release at a hippocampal synapse. Science 262:754-757.

Rosenmund C, Feltz A, Westbrook GL (1995) Synaptic NMDA receptor channels have a low open probability. J Neurosci 15:2788-2795.

Silver RA, Traynelis SF, Cull-Candy SG (1992) Rapid-time-course miniature and evoked excitatory currents at cerebellar synapses in situ. Nature 355:163-166.

Tong G, Jahr CE (1994) Multivesicular release from excitatory synapses of cultured hippocampal neurons. Neuron 12:51-59.

Traynelis SF, Cull-Candy SG (1990) Proton inhibition of $N$-methyl-Daspartate receptors in cerebellar neurons. Nature 345:347-350.

Twyman RE, Rodgers CJ, Macdonald RL (1990) Intraburst kinetic properties of the GABAA receptor main conductance state of the mouse spinal cord neurones in culture. J Physiol (Lond) 423:193-220. 